\title{
On the Necessity of Curriculumization of Labor Education in Primary and Middle Schools
}

\author{
Zhongping Yan * \\ Gongqing Vocational College of Science and Technology, Jiujiang 332020, Jiangxi, China.
}

Abstract: Following the call of General Secretary Xi at the National Education Conference in September 2018, labor education has set off an upsurge in the country. From kindergartens to primary and secondary schools, and even higher education institutions have established labor education-related courses in the field of education. Experts and scholars in China have also paid enough attention to the issue of labor education. In fact, labor education is not a new term in the field of education in the new era. For labor education to truly land, labor education must be curriculumized in primary and secondary schools. The curriculumization of labor education not only reflects the country's policy orientation towards labor education, At the same time, it is also a powerful guarantee for the scientific, standardized and effective labor education.

Keywords: Labor Education; Curriculum; Necessity

Labor education refers to "to enable students to fully experience the labor process through school courses, practical activities, and life labor, to cultivate the labor awareness, skills, spirit and habits necessary for students in future life and work, and to cultivate students to be respectful, love labor, independent and self-reliant. An educational form of social citizenship ${ }^{[1]}$."On September 10 , 2018, General Secretary Xi made it clear again at the National Education Conference: "We must promote the spirit of work among students, educate and guide students to uphold and respect work, and understand that work is the most glorious, noble, great, and beautiful work. The truth is that when you grow up, you can work hard, honestly, and creatively". ${ }^{[2]}$ From the perspective of education policy, labor education is highly evaluated, and at the same time, the education policy of "five education simultaneously" has been formally established in my country in the new era. In fact, in the new round of basic education curriculum reform that began in 2001, labor education has been incorporated into the overall national curriculum design as an important part of the comprehensive practical activity curriculum. However, due to the lack of understanding of the content and value of labor education, as well as the limitations of relevant conditions, it is difficult to normalize the establishment of primary and secondary schools in the specific implementation of labor education, and the achievement of related goals is also greatly reduced. Therefore, if labor education is to be truly implemented in primary and secondary schools, it is necessary to incorporate labor education into the curriculum system of primary and secondary schools, make it curriculum, and make it scientific, standardized, and serialized from the perspective of curriculum, and coordinate with other curriculums. Cooperate and jointly promote the all-round development of primary and secondary school students.

\section{The policy orientation of the curriculumization of labor education in primary and secondary schools}

The education concept of the new era believes that the comprehensive and individual development of students is the first essential point of education, and the goal of basic education is to cultivate the core qualities of students and promote the comprehensive and harmonious development of students in primary and secondary schools. This requires the basic principles of integration and diversification to provide elementary and middle school students with a more comprehensive and complete basic education curriculum system, and labor education is a beneficial supplement to school curriculum based on the existing curriculum system. Labor education is a form of educational practice that combines education and production practice. The purpose is to correct students' attitudes toward labor, master certain practical skills, and "form good habits of respecting labor, loving labor, being good at labor, and cherishing labor." To promote the overall development of individuals, to respond to the call of innovation and entrepreneurship, to build a life-long education system, and to realize the healthy development of society ${ }^{[3]}$."

In the early days of the founding of New China, the "Common Program of the Chinese People's Political Consultative Conference" included "love of labor" in the requirements of national merit, and a series of labor education activities were organized until the 1950s. After the reform and opening up to the end of the 21 st century, labor education paid more attention to the integration

Copyright (C) 2020 Zhongping Yan

doi: 10.18282/l-e.v9i4.1655

This is an open-access article distributed under the terms of the Creative Commons Attribution Non-Commercial License (http://creativecommons.org/licenses/by-nc/4.0/), which permits unrestricted non-commercial use, distribution, and reproduction in any medium, provided the original work is properly cited. 
of knowledge education, emphasizing mental labor and manual labor, and the policy of "grasping with both hands, both hands are hard", and labor education is no longer regarded as pure manual labor. The "Decision of the Central Committee of the Communist Party of China and the State Council on Deepening Education Reform and Comprehensive Promotion of Quality Education" on June 13, 1999 emphasized: "To implement quality education, moral education, intellectual education, physical education, and aesthetic education must be organically integrated in all links of educational activities. " With the development of modern science and technology, the slogan "Science and technology is the primary productive force" seems to pull the balance of education to the side of knowledge. Although labor education is still expressed as a component of education for all-round development, there is still no solid standardization and normalization. To establish the curriculum format, it was included under the banner of moral education. In 2001, the country started a new round of basic education curriculum reform, as an important part of the comprehensive practical activity curriculum, labor education has been formally included in the curriculum system. However, the comprehensive practical activity curriculum itself is an attempt of a new type of curriculum, and its mode of operation is still being explored, and labor education, as one of its many components, is easy to "flash in the pan" and is ignored. The 2010 "National Medium and Longterm Educational Reform and Development Plan Outline (2010-2020)" . ${ }^{[4]}$ once again emphasized the need to "strengthen labor education and cultivate students' love of labor and the love of working people".This concept is once again reminded of curriculum research Those who need to pay more attention to labor education, and emphasize the great significance of labor education for young students. On the eve of "May 1st" in 2015, General Secretary Xi delivered an important speech at the celebration of "May 1st" International Labor Day and the National Conference to Commend Model Workers and Advanced Workers and emphasized: "It is necessary to educate children to love labor and love Creation, through labor and creation, sow hope and reap the fruits, and also through labor and creation to hone the will and improve oneself." Advocate "support the Chinese dream with labor dream" . On July 24 of the same year, the Ministry of Education, the Communist Youth League, the Central Committee, and the National Youth Work Committee jointly issued the "Opinions on Strengthening Labor Education in Primary and Secondary Schools", focusing on the main objectives, basic principles, key implementation links and related guarantee mechanisms of labor education. Carried out a more detailed narrative and clarified the connotation of labor education. Under the guidance of this series of speeches and documents, the people of the whole country gradually paid attention to labor education. Many schools even combined the local natural conditions and cultural characteristics to link labor education and school-based curriculum development to carry out all kinds of labor education., And achieved certain results. For example, Yunnan Province has also compiled and distributed "local teaching materials for labor technology courses, which are provided to students free of charge, and relevant teacher training and seminars should be organized in a timely manner."[5] In September 2018, General Secretary Xi Jinping delivered a speech at the National Education Conference, formally incorporating labor education into China's general education policy in the new era, and established moral education, intellectual education, physical education, and aesthetic education. , Labor education "Five education simultaneously" education policy, this education policy once again illustrates the great significance of labor education to China's social development, education development and talent training, and provides policy support and guidance for labor education. From a national perspective, labor education has received unprecedented attention, and there are many researches on labor education in the academic field. However, labor education faces numerous obstacles in the specific implementation process. It has not been formally included in the school's curriculum and teaching plans from beginning to end, but only Occasionally as an off-campus practice or club activity, the process lacks standardization and continuity. Therefore, in order to standardize and normalize labor education, it is of great significance to the curriculum of labor education.

\section{The value orientation of the curriculumization of labor education in primary and secondary schools}

\section{(1) Curriculum is an inevitable requirement for the scientificization of labor education in primary and secondary schools}

The vigorous development of the cause of socialist modernization requires that the successors cultivated in our country in the future must be people with comprehensive development in morality, intelligence, physical education, and art. This is also the purpose of my country's education. Marx once said: "The young shoots of future education have sprouted from the factory system. For all children who have reached a certain age, future education is the combination of productive labor with intellectual education and sports. It is not only a way to improve social production. Method, and it's the only way to create a person with allround development." ${ }^{[6]}$ But for a long time, due to the influence of test-oriented education, labor education has been neglected. In addition, the long-term absence of formal labor education courses has made it difficult to achieve the goal of cultivating individuals for all-round development. With the new round of basic education curriculum reform, labor education has been further developed. The curriculumization of labor education is a further advancement of basic education curriculum reform and teaching reform. It is an important link in the process of promoting the all-round development of primary and middle school students. Our country responds to and supports the educational purpose of cultivating all-round people.

In order to realize the effective and orderly implementation of labor education, we must make every effort to promote the scientificization of labor education. The key to the scientization of education is to insist on the unity of teaching theory and practice. Dialectical materialism believes that practice is the ultimate goal of cognition, and cognition has a counterproductive effect on practice, and the two are dialectically unified. Therefore, labor education should never be a simple labor activity, equal to productive labor, and lose its own educational and scientific nature. Lenin believes that without the integration of the education of the young generation with productive labor, the ideal of the future society is unimaginable: whether it is teaching and education that is separated from productive labor, or productive labor without teaching and education at the same time, it cannot achieve modern technology. The level and the height required by the current state of scientific knowledge. ${ }^{[7]}$ On the one hand, true labor education should help students develop their potential, acquire knowledge, improve skills, and combine knowledge accumulation with the application of knowledge. The construction of a complete spiritual world provides guidance and contributes to the practice 
of the individual while cultivating the individual's spirit. In contrast, the labor education courses in many primary and middle schools today often rely on social practices or labor assignments. The content of labor is poor and single, and many of them are just one-time thematic labors, which are weakly related to the continuous development of students and are labor-intensive. The meaning is often superficial, and it is difficult to truly achieve the goal of labor education. If labor education is to be scientific, it is necessary to make labor education curriculum, incorporate labor education into the curriculum system of primary and secondary schools, clarify the purpose and significance of labor education, deepen understanding of labor education, and rationalize the content of labor education courses. The planning and design of labor education, strengthen the connection between labor education and other disciplines, make overall arrangements, and promote the realization of labor education goals.

(2)Curriculumization is the proper embodiment of promoting the standardization of labor education in primary and secondary schools

Curriculumization is an important means to ensure the standardized implementation of labor education and should be reflected. If labor education is not included in the formal curriculum arrangements and teaching plans of primary and secondary schools, and the curriculum standards for labor education are not required for class hours and evaluation, and the corresponding financial and material support for the development of labor education courses is not provided, The standardized implementation of labor education will be difficult to achieve. Therefore, the curriculumization of labor education is the recognition of the legitimacy of labor education and the guarantee of the legitimacy of labor education. Only by incorporating labor education into the formal compulsory curriculum system of primary and secondary schools, planning and designing labor education courses with reasonable standards, class hours, evaluation, and providing a fixed practice site and serialized design of main activities for labor education Labor education is implemented in a standardized and orderly manner. In addition to standardizing the implementation conditions of labor education, curricularization also provides evaluation criteria for the effectiveness of labor education. This undoubtedly ends the disordered state of labor education in the past, forcing labor education curriculum developers and implementers to adopt formal courses. As a standpoint, with curriculum standards as the yardstick, improve the effectiveness and orderliness of the labor education process and realize the standardized development of labor education. For example, the county-level overall promotion of labor education curriculum developed by Baoding City, Hebei Province, the county-level overall labor education curriculum planning, and the four sequential themes of student self-service, housework, collective public welfare labor, and community public welfare labor Various organizations coordinate with each other to establish a labor education curriculum resource development mechanism and a labor education curriculum implementation guarantee mechanism to ensure the standardized implementation of labor education.

\section{(3) Curriculumization is the actual way to ensure the effectiveness of primary and secondary labor education}

Since the founding of New China, our country has always had a tradition of labor education, which is mainly derived from our belief in Marxism and adheres to the educational philosophy of combining education with productive labor. However, looking at the achievements of labor education in the past, although there are certain practical significance, some illogical phenomena will inevitably appear. For example, in some special periods, labor education is confused with productive labor, focusing only on labor and neglecting education; and in the context of exam-oriented education, only focusing on knowledge transfer and neglecting moral education, physical education, and labor education. The most fundamental reason for these unreasonable phenomena lies in the misunderstanding of labor education, which separates the practicality and education of labor education, making it difficult for labor education to receive effective results. In addition, although the call for labor education in the national education policy has never stopped, formal labor education courses have been absent for a long time, resulting in long-term chaos and disorder in the labor education field.

The curriculumization of labor education can effectively improve the implementation of labor education and promote the effective implementation of labor education. First of all, the curriculumization of labor education is a confirmation of the legitimacy of labor education. In the past, the poor implementation of labor education was largely due to the fact that parents, students, and teachers did not pay much attention to it from the perspective of exam-taking. They believed that labor education was not a formal and required course, and one-sidedly believed that labor education was purely conducted. Practice. The curriculumization of labor education has confirmed the significance and value of labor education from the level of curriculum, deepened people's understanding of labor education, and attracted attention and actively participated in labor education activities. Secondly, as a practical educational activity, labor education involves the coordination of various organizations. It also requires human, material, and financial support from all parties, such as the training of professional instructors, the construction of fixed labor practice bases, etc. Only by curricularizing labor education can it attract the attention and support of all parties, especially the education authorities, and give the greatest support within their jurisdiction. Third, the setting of any curriculum has its value and significance. The curriculumization of labor education embodies the purpose and significance of labor education as labor education curriculum standards, and provides a certain evaluation scale for labor education curriculum evaluation. This standard and evaluation scale urges the implementers of labor education courses to search extensively for labor education curriculum resources, dig deeper into the meaning of each theme activity, develop sequential labor education curriculum content that promotes the sustainable development of students, and conduct practical activities on students. Professional guidance helps them communicate, summarize and share, and improve the effectiveness of labor education.

\section{References}

[1] Zhou Hongyu, Cheng Guangxu, Song Naiqing, Wang Xiaojie, Sun Miantao, Kang Cuiping, Chen Peng, Long Baoxin, Qi Zhanyong. Study and implement the spirit of the National Education Conference and accelerate the modernization of education[J]. 


\title{
Research on the Ways of People's Participation in Anti-terrorism from the Perspective of National Anti-terrorism
}

\author{
Zhiqiang Zhang * \\ People's Public Security University of China,100038,Beijing china.
}

\begin{abstract}
Anti-terrorism by the whole people is inseparable from the extensive participation of the people. Historical experience has shown that the people are the true source of strength and the deepest source of war's might. The anti-terrorist struggle is a fundamental contradiction between the enemy and ours. It is a long-lasting and long-term struggle. It requires the implementation of the fundamental strategy of "combination of prevention and combat, and the focus on prevention" and the extensive participation of the people. At present, the situation in the domestic fight against terrorism is still severe and complex, and there are still many problems in intelligence and information, group defense and group governance, and emergency rescue. To win the final victory in the fight against terrorism, we must create new ways for the people to participate in the fight against terrorism.
\end{abstract}

Keywords: Terrorism; National Anti-terrorism; Means

\section{Introduction}

Resolutely winning the fight against terrorism is an important part of safeguarding national security. With the implementation of the Anti-Terrorism Law, the concept of anti-terrorism for the whole people has been deeply rooted in the hearts of the people. The participation of the broad masses of the people in the fight against terrorism is conducive to expanding the anti-terrorism model of relying on professional forces, and to improve the overall level of anti-terrorism work capabilities; it is conducive to effectively resisting terrorist risks and creating a safe and stable social environment.

\section{The nature of the fight against terrorism}

\subsection{The fight against terrorism is the fundamental contradiction between the enemy and ours}

Terrorism is essentially against justice and anti-humanity. It is a flagrant trampling on human society and a common enemy of the international community. Terrorism aims to use violence, sabotage, intimidation and other means to create social panic, endanger public safety, infringe upon personal property, or coerce state agencies and international organizations to achieve its political and ideological purposes. Terrorist attacks against innocent civilians are even more serious crimes recognized worldwide. General Secretary Xi Jinping pointed out: "violent terrorist activities ignore basic human rights and trample on humanitarian justice, challenging the common bottom line of human civilization. It is neither an ethnic issue nor a religious issue, but the common enemy of all ethnic groups ${ }^{[1]}$."

\section{Copyright (C) 2020 Zhiqiang Zhang}

doi: 10.18282/1-e.v9i4.1656

This is an open-access article distributed under the terms of the Creative Commons Attribution Non-Commercial License (http://creativecommons.org/licenses/by-nc/4.0/), which permits unrestricted non-commercial use, distribution, and reproduction in any medium, provided the original work is properly cited.

Journal of Shaanxi Normal University (Philosophy and Social Sciences Edition),2018,47( 06): 5-28.

[2] "Xi Jinping emphasized at the National Education Conference on adhering to the development path of socialist education with Chinese characteristics, cultivating socialist builders and successors with comprehensive development of morality, intelligence, physical education, art and labor", Ministry of Education of the People's Republic of China website, 2018-09-10. http://www.moe. gov.cn/jyb_xwfb/s6052/moe_838/201809/t20180910_348145. html.

[3] Wang Lianzhao.On the characteristics and implementation of labor education[J].Chinese Journal of Education,2016(07):89-94.

[4] Gu Mingyuan, Shi Zhongying. Interpretation of the National Medium and Long-term Education Reform and Development Plan (2010-2020)[M]. Beijing: Beijing Normal University Press, 2010.

[5] Excerpts from the experience of strengthening primary and secondary school labor education in various regions[N]. China Education News, 2015-08-06(002).

[6] Xie Lilin. The role of labor education in the overall development of students[J].Journal of Educational Science of Hunan Normal University,2003(06):53-55. 